Article

\title{
Double Dose: High Family Conflict Enhances the Effect of Media Violence Exposure on Adolescents' Aggression
}

\section{Karin M. Fikkers *, Jessica Taylor Piotrowski, Wouter D. Weeda, Helen G. M. Vossen and Patti M. Valkenburg}

Amsterdam School of Communication Research ASCoR, University of Amsterdam, Kloveniersburgwal 48, 1012 CX Amsterdam, The Netherlands; E-Mails: j.piotrowski@uva.nl (J.T.P.); w.d.weeda1@uva.nl (W.D.W.); h.g.m.vossen@uva.nl (H.G.M.V.)p.m.valkenburg@uva.nl (P.M.V.)

* Author to whom correspondence should be addressed; E-Mail: k.m.fikkers@uva.nl; Tel.: +31-0-20-52-52-352.

Received: 10 May 2013; in revised form: 28 June 2013 / Accepted: 28 June 2013 /

Published: 5 July 2013

\begin{abstract}
We investigated how exposure to media violence and family conflict affects adolescents' subsequent aggressive behavior. We expected a double dose effect, meaning that high media violence exposure would lead to higher levels of aggression for adolescents in high conflict families compared to low conflict families. A total of 499 adolescents (aged 10 to $14,48 \%$ girls) participated in a two-wave longitudinal survey (4-month interval). Survey questions assessed their exposure to violence on television and in electronic games, family conflict, and aggressive behavior. Analyses revealed a significant interaction between media violence and family conflict. In families with higher conflict, higher media violence exposure was related to increased subsequent aggression. This study is the first to show a double dose effect of media violence and family conflict on adolescents' aggression. These findings underscore the important role of the family in shaping the effects of adolescents' media use on their social development.
\end{abstract}

Keywords: adolescents; aggression; family conflict; media violence 


\section{Introduction}

Media violence exposure has been investigated as a risk factor for aggressive behavior for decades, with most studies demonstrating small to moderate effect sizes [1,2]. Despite the current scientific debate about whether these effect sizes are theoretically and practically meaningful [3], such relatively small effects are neither strange nor unexpected. Aggression is a complex behavior caused by multiple factors $[4,5]$ of which media violence is only one. Research investigating the effects of media violence in concert with other predictors of aggression is needed in order to better understand its relative contribution to aggressive behavior $[4,6]$.

The debate about whether and how media violence leads to aggression has received renewed attention following the tragic event at Sandy Hook elementary school in December 2012, where 20 children and six teachers lost their lives. In the aftermath of this tragedy, President Obama called for additional funding for research designed to better understand the role that media violence may play in gun violence [7]. Public policy advocates such as Common Sense Media have indicated that "one of the most pressing needs" in both the public and scientific debate is research that investigates the effects of media violence within the context of the family environment [8]. Indeed, family conflict (defined as openly expressed anger, hostility, and aggression in the home [9]) has been identified as a risk factor for aggressive behavior, particularly during childhood and early adolescence [5]. Given that aggressive behavior is often conceptualized as the result of a socialization process in which both the family and the media play important roles [10], investigating how media violence affects aggression within the context of family conflict is relevant [11]. In this study, we respond to public and academic concerns by investigating the interactive effect of media violence and family conflict on adolescents' aggression.

\subsection{Research into Media Violence and Family Conflict}

Although media violence and family conflict have both been investigated as predictors of aggression [12-15], this has largely taken place in separate disciplines [16]. Media researchers have focused on the effects of media violence, while largely ignoring effects of family conflict, whereas the reverse is true for family researchers. Although a few studies have investigated the relative effect of media violence when controlling for family conflict (along with a number of other risk factors) [17,18], it has not yet been investigated whether media violence and family conflict have an interactive effect on aggressive behavior.

This lack of research attention for the joint effect of media violence and family conflict on aggression is surprising. Researchers have long argued that media research should incorporate social context as an integral part of research models rather than treat it as a control variable [19,20]. After all, media use does not occur in a social vacuum, but rather takes place within a broader social context that can shape and strengthen its effects [19-21]. Furthermore, investigating interaction effects between multiple predictors of aggression has been identified as an important goal for media research [22]. Doing so may show whether the relatively small effects of media violence exposure found on an aggregate level may be larger for a subgroup of children who are particularly vulnerable to the effects of media violence [22]. By ignoring relevant moderators such as family conflict, the effect of media 
violence on aggression may be 'diluted' across a study sample, potentially resulting in small effects [22]. To address this gap in the literature, we conducted a longitudinal survey among Dutch adolescents aged 10 to 14 to test whether there is an interactive effect of media violence and family conflict on adolescents' subsequent aggressive behavior.

\subsection{Theoretical Background}

Social Cognitive Theory (SCT) [10] has been used to explain the effects of both media violence and family conflict on aggressive behavior [19,23-28]. SCT states that children learn behaviors through their own experience and through observation of others. Seeing others enact a certain behavior and subsequently being punished or rewarded for this behavior teaches a child which behaviors are socially acceptable and which are not. Such social cognitions are seen as regulators of actual behavior [29-31].

Within this social learning process, the family and the media represent two observable role models for children and early adolescents [10]. Parents, in particular, are the most important role models for youth [32,33]. Through their own actions, parents provide information about acceptable and unacceptable social behavior, which children can then replicate. In the case of aggression, several studies have shown that children who observe conflict within their family display more aggressive behavior themselves [12,25,34,35].

Given the high amount of time that adolescents spend using media [36], characters and behaviors observed on TV and in games also form a vital part of adolescents' social learning process [19,24]. The way in which aggression is often portrayed in these media - glorified, rewarded, and performed by attractive characters [37] - further increases the chance that adolescents will also display such behavior. Indeed, experimental research has shown that children and adolescents who are exposed to rewarded violence or who identify with aggressive characters subsequently demonstrate increased aggressive behavior [37,38].

Two theoretical models would predict that observing aggression both in the media and in the family can create a "double dose" effect [21]. Cultivation theory includes the concept of resonance, which is the idea that people whose life experiences are congruent with what they see on television will be more affected by media messages [21]. The Differential Susceptibility to Media Effects Model [22] stresses that media effects are often conditional, and that social context can reinforce the effects of exposure to media violence. Based on these theories, we expect that adolescents with high media violence exposure will become more aggressive in the context of high family conflict (double dose effect) than in the context of low family conflict. Thus, we hypothesize that family conflict strengthens the effect of media violence on aggression. Investigating this moderating role of family conflict can help us understand which adolescents are particularly susceptible to the effects of media violence exposure.

\section{Method}

\subsection{Participants}

After receiving approval from the sponsoring institution's Institutional Review Board, a large, private survey research institute in the Netherlands (TNS-NIPO) collected the data. Adolescents were recruited through TNS-NIPO's existing online panel (approximately 60,000 households) that is 
representative of the Netherlands. 673 Dutch adolescents between the ages of 10 and 14 years completed an online survey in January 2012. In May 2012, 499 of these adolescents agreed to participate in a second survey (i.e., 74\% recontact agreement). These 499 adolescents made up the sample used in this study (85.8\% sibling pairs; $47.9 \%$ girls; age at Time $1: M=11.87, S D=1.46$ ).

\subsection{Measures}

\subsubsection{Media Violence Exposure}

Media violence exposure was measured using direct estimates, a measure frequently used in media research [39-41]. Exposure to violent content on TV and in electronic games was measured with two items each (four items in total): (1) How often do you watch television programs [play games] that contain violence? and (2) On the days that you watch television programs [play games] that contain violence, how much time do you spend on this per day? Participants were given the following definition of violence: 'All violence (for example, fighting and shooting) that living beings (for example, humans and monsters) do to each other.' Response categories for the first item ranged from 0 (never) to 7 (7 days per week). The second item was an open-ended question, answered by filling in hours and minutes. Items were multiplied to calculate the number of hours per week of violent television and violent game exposure. These two variables were then summed to create one variable representing violent media exposure in hours per week.

\subsubsection{Family Conflict}

Family conflict was measured using five items from the conflict subscale of the Family Environment Scale [9,42]. Respondents were asked to indicate how often family members do the following things at home: (1) criticize each other, (2) hit each other, (3) argue, (4) curse, and (5) become so angry they start throwing things. Response categories were (1) never, (2) almost never, (3) sometimes, and (4) often. Scores were averaged to create scales $(\alpha=0.75)$, with higher scores indicating greater family conflict.

\subsubsection{Aggression}

Adolescents' direct aggression was measured with six items adapted from the Direct and Indirect Aggression Scale [43]. Adolescents were asked how often in the past six months they had done the following things to another adolescent: (1) call names, (2) push in a rough way, (3) kick or hit, (4) threaten to beat up, (5) fought with, and (6) tripped on purpose. Response categories were (1) never, (2) 1 time in the past 6 months, (3) 2-3 times in the past 6 months, (4) about 1 time per month, (5) about 1 time per week, and (6) about every day. Scores were averaged to create scales $(\alpha=.83 / .85$ at Time $1 /$ Time 2$)$, with higher scores indicating greater aggressive behavior.

\subsection{Analytic Approach}

Because $86 \%$ of our sample ( 428 children) consisted of sibling pairs, ordinary least squares (OLS) regression was inappropriate because the assumption of independent observations is violated. This can 
result in over- or underestimation of coefficients due to biased estimates of standard errors [44,45]. To address this clustering in the data, multilevel modeling was used in SPSS 20. Multilevel models take into account that some variables are clustered or nested within other variables (in our case, children were nested within households). We accounted for the correlation among children within a household by allowing the mean aggression score (i.e., the intercept of the regression equation) to vary freely across households. This results in appropriate estimates of the standard errors for the regression coefficients [45]. Parameters in this multilevel model can be interpreted in the same way as OLS regression.

All models controlled for aggressive behavior at Time 1. In addition, we investigated whether gender would be a suitable covariate in our analyses. Because of the relatively short time lag between the data collection waves, as well as the considerable skewness introduced to our data when including gender, we had some concern that the gender-included model would result in incorrect estimates. Given that gender is often included in models investigating media violence and aggression (e.g., [46,47]), we opted to conduct two sets of analyses: one in which gender is omitted from the model, and one in which gender is treated as a covariate. Results from both analyses are reported in the text.

The two-way interaction was probed using the Johnson-Neyman technique [48]. This technique indicates where (i.e., at which values of a continuous moderator) the effect of an independent variable on a dependent variable is significant (at $p<0.05$ ). In this particular study, the Johnson-Neyman technique allows us to identify at which values of family conflict the relationship between media violence and aggressive behavior achieves statistical significance. Although the values obtained for these regions of significance are slightly less stable in multilevel models than in fixed-effects regression, this technique provides valuable information for the interpretation of interaction effects [49].

\section{Results}

\subsection{Descriptives and Intercorrelations}

Table 1 presents the means, standard deviations, and correlations for all model variables. Adolescents in our sample scored relatively low on aggressive behavior, with a mean of 1.52 $(S D=0.71$, scale range: 1 to 6$)$. Family conflict was also relatively infrequent in the sample, with a reported mean of 2.10 ( $S D=0.55$, scale range: 1 to 4$)$. On average, adolescents reported consuming 4.8 hours per week of media violence $(S D=8.30)$.

Gender correlated significantly with media violence exposure at Time 1 and aggressive behavior at Time 1 and 2. Boys were more aggressive on average than girls (boys: $M=1.70, S D=0.82$; girls: $M=1.32, S D=0.51$ ), and also reported about four times more media violence exposure (boys: $M=7.60$ hours per week, $S D=10.47$; girls: $M=1.80$ hours per week, $S D=2.71$ ).

Aggressive behavior was quite stable over time $(r=0.55, p<0.001)$. Significant correlations were found between media violence and aggressive behavior, both cross-sectionally $(r=0.27, p<0.001)$ and longitudinally $(r=0.18, p<0.001)$. Family conflict was also significantly related to aggressive behavior (cross-sectional $r=0.36, p<0.001$, longitudinal $r=0.30, p<0.001$ ). The two predictors, family conflict and media violence, correlated at $.11(p=0.02)$. 
Table 1. Means (standard deviations) and correlations for model variables.

\begin{tabular}{|l|c|c|c|c|c|c|c|c|}
\hline \multirow{2}{*}{ Variables } & \multicolumn{3}{|c|}{ Means (SD) } & \multicolumn{5}{c|}{ Correlations } \\
\cline { 2 - 10 } & Full sample & Boys & Girls & $\mathbf{1}$ & $\mathbf{2}$ & $\mathbf{3}$ & $\mathbf{4}$ & $\mathbf{5}$ \\
\hline 1. Aggression T1 & $1.52(0.71)$ & $1.70(0.82)$ & $1.32(0.51)$ & - & & & & \\
\hline 2. Media violence T1 & $4.82(8.30)$ & $7.60(10.47)$ & $1.80(2.71)$ & $0.27 * * *$ & - & & & \\
\hline 3. Family conflict T1 & $2.10(0.55)$ & $2.13(0.55)$ & $2.07(0.54)$ & $0.36^{* * *}$ & $0.11 *$ & - & & \\
\hline 4. Aggression T2 & $1.46(0.68)$ & $1.61(0.77)$ & $1.29(0.51)$ & $0.55^{* * *}$ & $0.18 * * *$ & $0.30 * * *$ & - & \\
\hline 5. Gender ${ }^{\text {a }}$ & - & - & - & $0.27 * * *$ & $0.35 * * *$ & 0.06 & $0.24 * * *$ & - \\
\hline
\end{tabular}

\subsection{Main Effects of Media Violence and Family Conflict}

We first investigated the main effect of media violence exposure on aggressive behavior in two steps: first while only controlling for Time 1 aggression, second by adding family conflict to the model. The two predictors (Time 1 media violence exposure and family conflict) and the control variable (Time 1 aggression) were standardized in order to obtain standardized regression coefficients in the multilevel analysis. Standardized regression coefficients $\left(b^{*}\right)$ are presented in the text; unstandardized coefficients are presented in Table 2. For the unstandardized coefficients $(b)$, the predictor variables were centered at their sample mean values to reduce multicollinearity problems with their interaction terms.

Although Time 1 media violence exposure and Time 2 aggression correlated significantly (as shown in Table 1), media violence was not a significant predictor of aggressive behavior when controlling for Time 1 aggression $\left(b^{*}=0.02, p=0.47\right)$. When family conflict was added to the model, the relationship between media violence and aggression was unchanged $\left(b^{*}=0.02, p=0.48\right)$. Family conflict did predict subsequent aggression $\left(b^{*}=0.08, p=0.003\right)$, with increased family conflict predicting increased aggression. These results did not change when we added gender to the model as covariate: media violence was not associated with subsequent aggression $\left(b^{*}=-0.00\right.$, $p=0.89)$ whereas family conflict was $\left(b^{*}=0.08, p=0.002\right)$.

Table 2. Unstandardized regression coefficients, standard errors, and $95 \%$ confidence intervals (CI) predicting Time 2 aggressive behavior.

\begin{tabular}{|c|c|c|c|c|c|c|}
\hline \multirow{2}{*}{ Parameters } & \multicolumn{3}{|c|}{ Main effects } & \multicolumn{3}{|c|}{ Two-way interaction } \\
\hline & $b$ & $S E$ & $95 \%$ CI & $b$ & $S E$ & $95 \%$ CI \\
\hline \multicolumn{7}{|c|}{ Regression coefficients (fixed effects) } \\
\hline Intercept & $1.46 * * *$ & 0.03 & {$[1.40 ; 1.51]$} & $1.45 * * *$ & 0.03 & {$[1.40 ; 1.50]$} \\
\hline Aggression Time 1 & $0.47 * * *$ & 0.04 & {$[0.39 ; 0.55]$} & $0.46 * * *$ & 0.04 & {$[0.38 ; 0.54]$} \\
\hline MVE & 0.00 & 0.00 & {$[-0.00 ; 0.01]$} & 0.00 & 0.00 & {$[-0.00 ; 0.01]$} \\
\hline $\mathrm{FC}$ & $0.15 * *$ & 0.05 & {$[0.05 ; 0.25]$} & $0.14 * *$ & 0.05 & {$[0.04 ; 0.24]$} \\
\hline $\mathrm{MVE} * \mathrm{FC}$ & - & - & - & $0.01 *$ & 0.01 & {$[0.00 ; 0.03]$} \\
\hline \multicolumn{7}{|c|}{ Variance components (random effects) } \\
\hline Random intercept & $0.04^{\dagger}$ & 0.02 & {$[0.01 ; 0.12]$} & $0.04^{\dagger}$ & 0.02 & {$[0.01 ; 0.12]$} \\
\hline
\end{tabular}

Note: $\mathrm{MVE}=$ Media Violence Exposure; FC $=$ Family Conflict. For ease of readership, Table 2 reflects the analyses without gender. ${ }^{\dagger} p<0.10,{ }^{*} p<0.05,{ }^{* *} p<0.01,{ }^{* * *} p<0.001$. 


\subsection{Interaction between Media Violence and Family Conflict}

Following main effects testing, we tested our hypothesis that media violence exposure leads to more aggression in the context of high family conflict (i.e., double dose) than in the context of low family conflict. Results supported the double dose effect. There was a significant two-way interaction between media violence and family conflict $\left(b^{*}=0.06, p=0.01\right)$. The Johnson-Neyman technique indicated that the effect of media violence on aggression was significant only at higher values of family conflict, that is, for scores of 2.44 or higher on the four-point family conflict scale. As shown in Figure 1, high media violence exposure in combination with higher levels of family conflict led to increased aggression — providing evidence for a double-dose effect.

The double dose effect was also found when we included gender as covariate in the model. The interaction between media violence and family conflict remained significant $\left(b^{*}=0.06, p=0.02\right)$. The effect of media violence on aggression was again found for higher levels of family conflict (in this analysis, for scores of 2.95 and higher on the family conflict scale). The Johnson-Neyman technique also indicated a significant effect of media violence on aggression for low family conflict (i.e., scores of 1.37 and lower on a scale ranging from 1 to 4 ). For low conflict families, the pattern observed was the reverse: increased media violence was related to decreased aggression. However, we are cautious to interpret this result, as it may reflect an artifact of the data given (a) the conservative nature of the gender-controlled analyses, (b) the limited range of this effect ( 0.37 data points on the 4-point scale), and (c) the low number of adolescents with high media violence and low family conflict scores $(n=4)$.

Figure 1. High media violence exposure and high family conflict lead to increased aggression in adolescents $(*=$ significant at $p<0.05)$. Note: low, mean, and high family conflict represent values of $1.76,2.10$, and 2.44 on the family conflict scale.

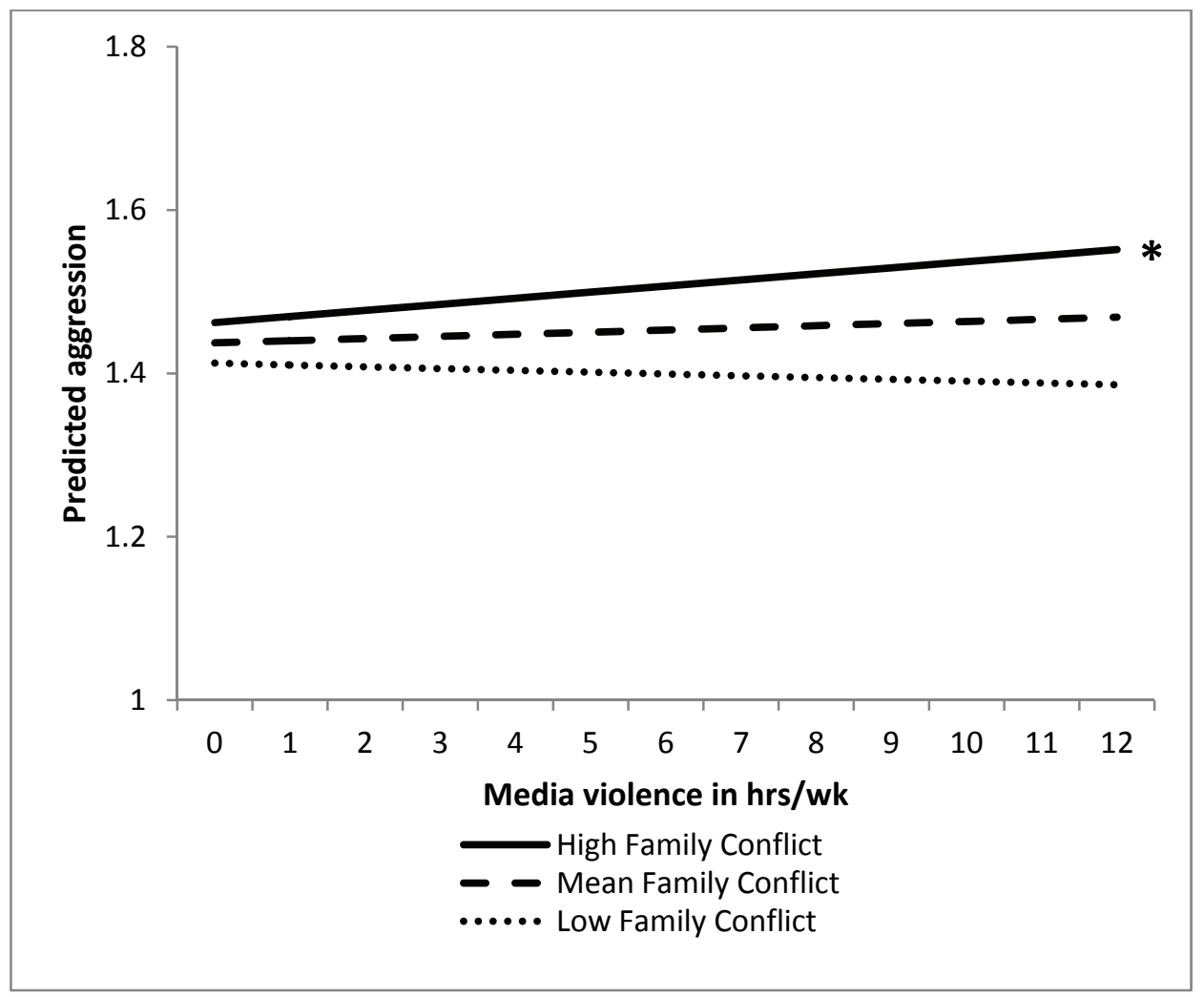




\section{Discussion}

This study investigated the interactive effect of media violence exposure and family conflict on adolescents' aggressive behavior. We found support for the hypothesized double dose effect: Adolescents' aggression increased when they were exposed to both high media violence and high family conflict. This finding provides three important implications for research and practice. First, the presence of a double dose effect is consistent with the idea that not all media consumers are affected by media violence in the same way [22]. Although many studies have shown main effects of media violence on aggression (e.g., $[14,15,18]$ ), our study shows that media violence exposure may have a stronger effect on adolescents from particular social contexts. By identifying and testing when media violence may have a stronger effect on aggression, rather than expecting equal effects for all media consumers, our study contributes to a more nuanced understanding of the effects of media violence. Further research that seeks to investigate other potential moderators of the media violence-aggression relationship would be worthwhile.

Second, our findings highlight the importance of incorporating social context in media research. Adolescents living in higher conflict families showed increased aggressive behavior as a result of higher media violence exposure. One explanation for such a double dose effect is that more frequent experiences with aggression - both directly via family members and indirectly via the media — lead to more accessible aggression-related scripts in adolescents' memory [24,25]. Having more readily accessible aggressive scripts increases the likelihood of using aggressive behavior in social interactions [50]. A second way in which frequent exposure to aggression in both the family and the media may lead to increased aggression is via adolescents' social norms. High media violence consumers in high conflict families can learn from two social contexts that aggression is acceptable social behavior [31]. Such normative beliefs have been shown to predict increased aggression [29,30,51]. Finally, a double dose effect may be explained by maladaptive processing of social information. Research has shown that children living in family environments characterized by high levels of negative emotional expression are more likely to experience maladaptive processing styles and subsequent conduct problems [52]. Maladaptive processing styles are operationalized as hostile attribution bias (i.e., a tendency to view others' intentions as mean) and maladaptive response generation (i.e., when presented with a negative situation, children generate aggressive response solutions as opposed to more prosocial response options). It may be that children growing up in households with high family conflict and high media violence exposure develop maladaptive processing styles and, as a result, demonstrate increased aggression. Currently, it is unknown which of these three mechanisms - aggressive scripts, normative beliefs, or maladaptive processing-may explain this double dose effect. Research which seeks to identify how a combination of real-life aggression and media aggression leads to increased aggressive behavior in adolescents would advance our understanding of this effect.

Third, our findings provide a starting point for practitioners who work on the prevention or reduction of adolescents' aggressive behavior. Given that family conflict not only predicted aggression individually, but also strengthened the effect of media violence on aggression, it seems reasonable that most ground can be gained by reducing aggression within the family. Family members' aggressive behavior may have a more pronounced influence on adolescents' aggression compared to media 
violence due to their proximity and emotional closeness to the adolescent [11]. Helping family members in high conflict families to recognize and change their norms about acceptable and unacceptable social behavior would be a fruitful first step towards reducing adolescents' aggressive behavior. However, it is important to recognize that changing household norms and reducing family conflict may not always be easy to achieve, particularly in high conflict families. For these families, our results speak to the benefit of reducing media violence as an alternative way of decreasing adolescents' aggressive behavior.

\section{Limitations}

It is important to recognize that the effect sizes found in our study were relatively small. In fact, despite a significant bivariate correlation between media violence and aggression, this study did not find a main effect of media violence exposure on aggression - a finding inconsistent with previous research (e.g., [14,15,18]). Although small effects are not uncommon in media research [3], three methodological choices should be taken into account when interpreting our results. First, our choice of media violence exposure measure may have resulted in underestimation of the effect sizes found. This measure asked adolescents to report how often and how long they consume violent TV shows and violent games during the week. Although such direct estimates have been validated for use among adolescents [41,53], the estimation procedures involved in these measures can be difficult for adults and adolescents alike, potentially resulting in over- or underestimation of their actual exposure [54]. Consequently, the small but significant effect sizes found in our study, as well as the absence of a significant main effect of media violence on aggressive behavior, may be partly due to our choice of media violence measure.

Second, the time lag between waves in our study was relatively short (four months). Since aggressive behavior was quite stable in our study (see the longitudinal correlation between Time 1 and Time 2 aggression in Table 1), this time lag may have been too short to show larger effects of media violence and family conflict on aggression. Third, our sample consisted of typically-developing adolescents who scored relatively low on media violence, family conflict, and aggressive behavior. Because of the restricted range of scores on these variables, the relationships between them may have been attenuated. Still, despite these caveats, we found a double dose effect of media violence and family conflict on adolescents' subsequent aggression, which speaks to the strength of this effect. Future studies may find this effect to be stronger when investigating it in a study with a longer time lag and an at-risk sample in which media violence, family conflict and aggressive behavior are more frequent. Furthermore, replication of our study using a measure of media violence exposure that relies less on adolescents' estimates of media use across longer periods (such as the Favorites measure by Anderson and Dill [55]) would be an appropriate next step.

\section{Conclusion}

This study is the first to investigate the interactive effect of media violence and family conflict on adolescents' aggression. Results showed that media violence may be a stronger risk factor for adolescents in high conflict families compared to those in low conflict families. Our findings are a first step towards improving the public and scientific understanding of whether and how media violence 
leads to aggression in the context of other risk factors [8,11,22]. Practically speaking, these findings underscore the important role of the family in the development of early adolescents' social behavior. It is important for parents to realize that their home environment can strengthen the effect of media violence on their child's aggressive behavior. Fostering discussions about what constitutes acceptable social behavior, both in the media and in real life, can be a useful way for parents to mitigate potential negative effects of violent media exposure.

\section{Acknowledgments}

The research was supported by a grant to the fifth author from the European Research Council under the European Union's Seventh Framework Programme (FP7/2007-2013)/ERC grant agreement no [AdG09 249488-ENTCHILD].

\section{Conflict of Interest}

The authors declare no conflict of interest.

\section{References}

1. Anderson, C.A.; Shibuya, A.; Ihori, N.; Swing, E.L.; Bushman, B.J.; Sakamoto, A.; Rothstein, H.R.; Saleem, M. Violent video game effects on aggression, empathy, and prosocial behavior in Eastern and Western countries: A meta-analytic review. Psychol. Bull. 2010, 136, 151-173.

2. Bushman, B.J.; Huesmann, L.R. Short-term and long-term effects of violent media on aggression in children and adults. Arch. Pediatr. Adolesc. Med. 2006, 160, 348-352.

3. Valkenburg, P.M.; Peter, J. Five challenges for the future of media-effects research. Int. J. Comm. 2013, 7, 197-215.

4. Browne, K.D.; Hamilton-Giachritsis, C. The influence of violent media on children and adolescents: A public-health approach. Lancet 2005, 365, 702-710.

5. Ribeaud, D.; Eisner, M. Risk factors for aggression in pre-adolescence: Risk domains, cumulative risk and gender differences-Results from a prospective longitudinal study in a multi-ethnic urban sample. Eur. J. Criminol. 2010, 7, 460-498.

6. Bandura, A. Social cognitive theory of mass communication. In Media Effects: Advances in Theory and Research; Bryant, J., Oliver, M.B., Eds.; Routledge: New York, NY, USA, 2009; pp. 94-123.

7. White House. Available online: http://www.whitehouse.gov/photos-and-video/video/2013/01/16/ president-obama-introduces-plan-reduce-gun-violence/ (accessed on 21 February 2013).

8. Common Sense Media. Media and violence: An analysis of current research. 2013. Available online: http://www.commonsensemedia.org/research/media-and-violence-an-analysis-of-currentresearch/ (accessed on 18 February 2013).

9. Moos, R.H.; Moos, B.S. Family Environment Scale Manual, 3rd ed.; Consulting Psychologist Press: Palo Alto, CA, USA, 1994.

10. Bandura, A. Social Foundations of Thought and Action: A Social Cognitive Theory; Prentice Hall: Englewood Cliffs, NJ, USA, 1986. 
11. Ferguson, C.J. Media violence effects: Confirmed truth or just another X-File? J. Forensic Psychol. Pract. 2009, 9, 103-126.

12. Tanaka, A.; Raishevich, N.; Scarpa, A. Family conflict and childhood aggression: The role of child anxiety. J. Interpers. Violence 2010, 25, 2127-2143.

13. Vandewater, E.; Lansford, J. Influences of family structure and parental conflict on children's well-being. Fam. Relat. 1998, 47, 323-330.

14. Gentile, D.A.; Coyne, S.; Walsh, D.A. Media violence, physical aggression, and relational aggression in school age children: A short-term longitudinal study. Aggress. Behav. 2011, 37, 193-206.

15. Krahé, B.; Möller, I. Longitudinal effects of media violence on aggression and empathy among German adolescents. J. Appl. Dev. Psychol. 2010, 31, 401-409.

16. Vandewater, E.; Lee, J.; Shim, M. Family conflict and violent electronic media use in school-aged children. Media Psychol. 2005, 7, 73-86.

17. Ferguson, C.J.; San Miguel, C.; Hartley, R.D. A multivariate analysis of youth violence and aggression: The influence of family, peers, depression, and media violence. J. Pediatr. 2009, 155, 904-908.

18. Huesmann, L.R.; Moise-Titus, J.; Podolski, C.; Eron, L.D. Longitudinal relations between children's exposure to TV violence and their aggressive and violent behavior in young adulthood: 1977-1992. Dev. Psychol. 2003, 39, 201-221.

19. Jordan, A. The role of media in children's development: An ecological perspective. J. Dev. Behav. Pediatr. 2004, 25, 196-206.

20. Slater, M.D.; Snyder, L.; Hayes, A.F. Thinking and modeling at multiple levels: The potential contribution of multilevel modeling to communication theory and research. Hum. Commun. Res. 2006, 32, 375-384.

21. Gerbner, G.; Gross, L.; Morgan, M.; Signorielli, N. The mainstreaming of America: Violence profile no. 11. J. Commun. 1980, 30, 10-29.

22. Valkenburg, P.M.; Peter, J. The differential susceptibility to media effects model. J. Commun. 2013, 64, 221-243.

23. Anderson, C.A.; Bushman, B.J. Human aggression. Annu. Rev. Psychol. 2002, 53, 27-51.

24. Huesmann, L.R. The impact of electronic media violence: Scientific theory and research. J. Adolesc. Health 2007, 41, S6-S13.

25. Farver, J.A.M.; Xu, Y.Y.; Eppe, S.; Fernandez, A.; Schwartz, D. Community violence, family conflict, and preschoolers' socioemotional functioning. Dev. Psychol. 2005, 41, 160-170.

26. Margolin, G.; Gordis, E.B. The effects of family and community violence on children. Annu. Rev. Psychol. 2000, 51, 445-479.

27. McKelvey, L.M.; Whiteside-Mansell, L.; Bradley, R.H.; Casey, P.H.; Conners-Burrow, N.A.; Barrett, K.W. Growing up in violent communities: Do family conflict and gender moderate impacts on adolescents' psychosocial development? J. Abnorm. Child Psychol. 2011, 39, 95-107.

28. Proctor, L.J. Children growing up in a violent community: The role of the family. Aggress. Violent Beh. 2006, 11, 558-576.

29. Huesmann, L.R.; Guerra, N.G. Children's normative beliefs about aggression and aggressive behavior. J. Pers. Soc. Psychol. 1997, 72, 408-419. 
30. Perry, D.G.; Perry, L.C.; Rasmussen, P. Cognitive social-learning mediators of aggression. Child Dev. 1986, 57, 700-711.

31. Orue, I.; Bushman, B.J.; Calvete, E.; Thomaes, S.; Orobio de Castro, B.; Hutteman, R. Monkey see, monkey do, monkey hurt: Longitudinal effects of exposure to violence on children's aggressive behavior. Soc. Psychol. Person. Sci. 2011, 2, 432-437.

32. Anderson, K.R.; Cavallaro, D. Parents or pop culture? Children's heroes and role models. Childhood Educ. 2002, 78, 161-168.

33. Bricheno, P.; Thornton, M. Role model, hero or champion? Children's views concerning role models. Educ. Res. 2007, 49, 383-396.

34. Duncan, S.C.; Strycker, L.A.; Duncan, T.E.; Okut, H. A multilevel contextual model of family conflict and deviance. J. Psychopathol. Behav. 2002, 24, 169-175.

35. Formoso, D.; Gonzales, N.A.; Aiken, L.S. Family conflict and children's internalizing and externalizing behavior: Protective factors. Am. J. Community Psychol. 2000, 28, 175-199.

36. Rideout, V.J.; Foehr, U.G.; Roberts, D.F. Generation M2. Media in the Lives of 8- to 18-YearOlds. 2010. Available online: http://kff.org/other/poll-finding/report-generation-m2-media-in-thelives/ (accessed on 14 December 2011).

37. Konijn, E.A.; Nije Bijvank, M.; Bushman, B.J. I wish I were a warrior: The role of wishful identification in the effects of violent video games on aggression in adolescent boys. Dev. Psychol. 2007, 43, 1038-1044.

38. Boyatzis, C.J.; Matillo, G.M.; Nesbitt, K.M. Effects of the "Mighty Morphin Power Rangers" on children's aggression with peers. Child Study J. 1995, 25, 45-55.

39. Vandewater, E.A.; Lee, S. Measuring children's media use in the digital age: Issues and challenges. Am. Behav. Sci. 2009, 52, 1152-1176.

40. Lee, C.; Hornik, R.; Hennessy, M. The reliability and stability of general media exposure measures. Commun. Methods Meas. 2008, 2, 6-22.

41. Schmitz, K.H.; Harnack, L.; Fulton, J.E.; Jacobs, D.R.; Gao, S.; Lytle, L.A.; van Coevering, P. Reliability and validity of a brief questionnaire to assess television viewing and computer use by middle school children. J. School Health 2004, 74, 370-377.

42. Jansma, J.B.M.; Coole, R.L. GKS-II, Gezins Klimaat Schaal. Handleiding; Swets \& Zeitlinger: Lisse, The Netherlands, 1996.

43. Björkqvist, K.; Lagerspetz, K.M.J.; Kaukiainen, A. Do girls manipulate and boys fight? Developmental trends in regard to direct and indirect aggression. Aggress. Behav. 1992, 18, 117-127.

44. Hayes, A.F. A primer on multilevel modeling. Hum. Commun. Res. 2006, 32, 385-410.

45. Desai, M.; Begg, M.D. A comparison of regression approaches for analyzing clustered data. Am. J. Public Health 2008, 98, 1425-1429.

46. Hopf, W.H.; Huber, G.L.; Weiss R.H. Media violence and youth violence: A 2-year longitudinal study. J. Media Psychol. 2008, 20, 79-96.

47. Krahé, B.; Busching, R.; Möller, I. Media violence use and aggression among German adolescents: Associations and trajectories of change in a three-wave longitudinal study. Psychol. Popular Media Cult. 2012, 1, 152-166. 
48. Preacher, K.J.; Curran, P.J.; Bauer, D.J. Computational tools for probing interaction effects in multiple linear regression, multilevel modeling, and latent curve analysis. J. Educ. Behav. Stat. 2006, 31, 437-448.

49. Bauer, D.J.; Curran, P.J. Probing interactions in fixed and multilevel regression: Inferential and graphical techniques. Multivar. Behav. Res. 2005, 40, 373-400.

50. Lösel, F.; Bliesener, T.; Bender, D. Social information processing, experiences of aggression in social contexts, and aggressive behavior in adolescents. Crim. Justice Behav. 2007, 34, 330-347.

51. Henry, D.; Guerra, N.; Huesmann, R.; Tolan, P.; VanAcker, R.; Eron, L. Normative influences on aggression in urban elementary school classrooms. Am. J. Community Psychol. 2000, 28, 59-81.

52. Schultz, D.; Shaw, D.S. Boys' maladaptive social information processing, family emotional climate, and pathways to early conduct problems. Soc. Dev. 2003, 12, 440-460.

53. Van der Voort, T.H.A.; Vooijs, M.W. Validity of children's direct estimates of time spent television viewing. J. Broadcast. Electron 1990, 34, 93-99.

54. Robinson, J.P.; Godbey, G. Time for Life: The Surprising Ways Americans Use Their Time; Pennsylvania State University Press: University Park, PA, USA.

55. Anderson, C.A.; Dill, K.E. Video games and aggressive thoughts, feelings, and behavior in the laboratory and in life. J. Pers. Soc. Psychol. 2000, 78, 772-790.

(C) 2013 by the authors; licensee MDPI, Basel, Switzerland. This article is an open access article distributed under the terms and conditions of the Creative Commons Attribution license (http://creativecommons.org/licenses/by/3.0/). 